\title{
Healthcare Provider's Perception and Attitude of Medications in Kingdom of Saudi Arabia
}

\author{
Yousef Ahmed Alomi ${ }^{1, *}$, Dima Ahmad Alaskari², Malak Mohammad Almelfi², Dima Ali Badawi ${ }^{3}$, \\ Abdullah Mohammad Alshihri ${ }^{4}$ \\ ${ }^{1}$ The Past General Manager of General Administration of Pharmaceutical Care and The Past Head, National Clinical pharmacy \\ and pharmacy practice and Pharmacy $R$ and D Administration, Ministry of Health, Riyadh, KSA. \\ ${ }^{2}$ General Administration of Pharmaceutical Care, Ministry of Health, Riyadh, SAUDI ARABIA. \\ ${ }^{3}$ Pharmaceutical Care Services, Saudi Germany Hospital, Aseer, SAUDI ARABIA. \\ ${ }^{4}$ Head, Pharmaceutical Care Services, Abha Maternity and Children Hospital, Abha, SAUDI ARABIA.
}

Received: 02 June 2018;

Accepted: 28 August 2018

*Correspondence to:

Dr. Yousef Ahmed Alomi,

The Past General Manager of General Administration of Pharmaceutical Care The Past Head, National Clinical pharmacy and pharmacy practice

Head, Pharmacy $R$ and $D$ Administration Ministry of Health, P.O.BOX 100, Riyadh 11392, Riyadh, SAUDI ARABIA.

Email: yalomi@gmail.com

Copyright: (C) the author(s),publisher and licensee Indian Academy of Pharmacists. This is an open-access article distributed under the terms of the Creative Commons Attribution Non-Commercial License, which permits unrestricted non-commercial use, distribution, and reproduction in any medium, provided the original work is properly cited.

\begin{abstract}
Objective: To explore Healthcare provider's perception of medications in Kingdom of Saudi Arabia. Methods: It is a 4-months cross-sectional survey of healthcare professionals and knowledge of medicines. The survey consisted of two-part demographic information and second part forty-nine questions divided into four domains. It included domain one: Primary or essential information about healthcare providers medication, domain two: healthcare professionals information about the drug-related problem, domain three: healthcare professionals information about drug-related cost and domain four: Healthcare providers perception of medications. All type of healthcare professionals included in the study. Medline Plus health information and DailyMed-INH elements information from National Institute of Health United State of America were used. The survey was distributed through social media by using what's App to more than one thousand healthcare professionals overall Kingdom of Saudi Arabia. The survey was made in an electronic format and it analyzed domain four: Healthcare provider's perception of medications through survey monkey system. Results: The total responders were (188) Healthcare professionals. Of those 177 (95.16\%) were Saudi and $9(4.84 \%)$ were non-Saudi. The gender distribution 120 (63.83\%) were females and 68 (36.17\%) were males. The most of Healthcare professionals were pharmacists $93(71.54 \%)$, followed by nurses $18(13.85 \%)$ and physicians 15 (11.54\%). The responders showed that 60 (32.26\%) takes their medication without any prior information, 110 (59.14\%) described drug to the person had the same disease and $130(70.27 \%)$ use the medication without a prescription. Also, 65 (35.33\%) of responders stopped their medication when they feel better and $116(63.04 \%)$ of them completed entire medication course of therapy. The responders displayed that 119 (63.98\%) believed Drug Information given by health care was not enough and $68(36.56 \%)$ of responders thought that their medication knowledge was not enough. Conclusion: To better educate clinicians and pharmacists about medications, some professionals Should be resourced. These resources include information specific to classes of medications and medication types that have high specific potential, as well as suggestions on how to assess function and Counsel Participant's information and knowledge of Medication's Perception.
\end{abstract}

Key words: Healthcare professional, Perception, Attitudes, Medications, Ministry of Health, Saudi Arabia.

\section{INTRODUCTION}

All the healthcare professionals have different knowledge of drug information and consent of their specialties. The physicians focus on medications prescribing and write the medications appropriately. The pharmacist's concern about how to prepare the medications and dispense the medications. While the nurse's consent of medications administration and transcription. With a wide variety of healthcare professional's knowledge, the perception and behavior also are different. Some physician is overprescribing the medications out of their specialties; the patient does not like to take medications because of adverse drug reaction and nurses administer the medications out of their specialties regardless of the updated medication knowledge recommendations. Healthcare providers play the essential role in empowering patients with the necessary skills and knowledge of perception medication. The current study evaluates the knowledge about medication and understands the level of self-rated physician knowledge; aim to identify factors influencing perception and attitude And Formative education on prescribing, enhanced health care professionals' understanding about the safe and effective medication use with improved recognition and avoidance of prescribing errors. Achieving therapeutic effectiveness and optimal outcomes for patients receiving some drugs remains complex. It often a challenge for pharmacists and other healthcare professionals. That has related the influence of genomics, comorbidities, patient's age, additional prescription and over the counter medications, herbal products and dietary variability. ${ }^{[1]}$ The provision of healthcare does not stop at the availability of essential drugs but includes the provision of adequate information to patients for the proper use of those drugs to achieve a full health potential. ${ }^{[2]}$ The Inadequate knowledge of 
prescribed medications among patients also known to associate with reduced compliance. There is some evidence that suggested improving knowledge of the disease condition also improves patient adherence to medication and improve quality of life..$^{[3-4]} \mathrm{Few}$ studies investigated the healthcare attitudes and medications perceptions. ${ }^{[-7]}$ Most of the studies focused on particular specialty, not a common perception. It is hard to find local in Gulf or Middle East counties. The goal of this study was to explore the health practitioner attitudes and perceptions about medications in Kingdom of Saudi Arabia.

\section{METHODS}

It is a 4-months cross-sectional survey of healthcare professionals and knowledge of medicines. The survey consisted of two-part, demographic information and second part forty-nine questions divided into four domains. ${ }^{[8]}$ It included domain one: Primary or essential information about healthcare providers medication, domain two: healthcare professionals information about the drug-related problem, domain three: healthcare professionals information about drug-related cost and domain four: Healthcare providers perception of medications. All type of healthcare professionals included in the study. ${ }^{[9-10]}$ Medline Plus health information and DailyMed-INH elements information from National Institute of Health United State of America were used. ${ }^{[11-12]}$ The 5 -point Likert response scale system was used. The questions were open and closed-ended. The survey was distributed through social media by using what's App to more than one thousand healthcare professionals overall Kingdom of Saudi Arabia. A message reminder was sent to healthcare professional after two weeks and additional message reminder was sent to healthcare professional after four weeks. The survey was made in an electronic format and it analyzed domain four: Healthcare provider's perception of medications through survey monkey system.

\section{RESULTS}

The total responders were (188) Healthcare professionals. Of those 177 (95.16\%) were Saudi and $9(4.84 \%)$ were non-Saudi. The gender distribution $120(63.83 \%)$ were females and $68(36.17 \%)$ were males. The majority of them in age (18-44) 86.7\% and located at Asir region 89 (47.34\%) and Riyadh region $46(24.5 \%)$. The most of Healthcare professionals were pharmacists $93(71.54 \%)$, followed by nurses $18(13.85 \%)$ and physicians $15(11.54 \%)$. The most responders had the Bachelor Degree 126 (67.02\%) followed by Diploma 33 (17.55\%) and Master degree 22 (11.7\%) The most type of medications used was anti-hypertension medicines, anti-diabetic medicines, Skin medications and drugs for Respiratory Diseases. Also, the most number of medication taken either one $29(15.85 \%)$ or two 17 (9.29\%) as explored in Table 1. More than one-third of healthcare professionals sometimes had difficulties in reading drug name 69 (37.5\%) and 20 (10.75\%) cannot know the expiration date of Medications. The responders showed that 60 $(32.26 \%)$ takes their medication without any prior information, $110(59.14 \%)$ described drug to the person had the same disease and $130(70.27 \%)$ use the medication without a prescription. Also, $65(35.33 \%)$ of responders stopped their medication when they feel better and 116 (63.04\%) of them they completed entire medication course of therapy. The responders displayed that $119(63.98 \%)$ believed that Drug Information given by health care was not enough and $68(36.56 \%)$ of responders, thought that their medication knowledge was not sufficient as explored in Table 2.

\section{DISCUSSION}

The Ministry of Health released the healthcare strategic plan with logo patient first. ${ }^{[13]}$ The pharmacy administration released several services according to the new pharmacy and healthcare strategic planning. ${ }^{[14]}$ The universal program was national medication safety program to cover all primary Heath care centers. ${ }^{[15]}$ The primary objective of the program was to identify and prevent drug-related problems; through healthcare provider's

\begin{tabular}{|c|c|c|}
\hline Characteristics & Response N & Response \% \\
\hline \multicolumn{3}{|l|}{ Sex } \\
\hline Female & 120 & $63.83 \%$ \\
\hline Male & 68 & $36.17 \%$ \\
\hline Answered question & 188 & $100 \%$ \\
\hline Skipped question & 0 & \\
\hline \multicolumn{3}{|l|}{ Nationality } \\
\hline Saudi & 177 & $95.16 \%$ \\
\hline Non-Saudi & 9 & $4.84 \%$ \\
\hline Answered question & 186 & $100 \%$ \\
\hline Skipped question & 2 & \\
\hline \multicolumn{3}{|l|}{ Age } \\
\hline$<18$ & 5 & $2.66 \%$ \\
\hline $18-29$ & 112 & $59.57 \%$ \\
\hline $30-44$ & 51 & $27.13 \%$ \\
\hline $45-59$ & 19 & $10.11 \%$ \\
\hline $60+$ & 1 & $0.53 \%$ \\
\hline Answered question & 188 & $100 \%$ \\
\hline Skipped question & 0 & \\
\hline \multicolumn{3}{|l|}{ Healthcare professional } \\
\hline Doctor & 15 & $11.54 \%$ \\
\hline Dentist & 4 & $3.08 \%$ \\
\hline Pharmacist & 93 & $71.54 \%$ \\
\hline Nurse & 18 & $13.85 \%$ \\
\hline Others & 33 & $25.38 \%$ \\
\hline Answered question & 130 & \\
\hline Skipped question & 58 & \\
\hline \multicolumn{3}{|l|}{ Total Experiences } \\
\hline Doctorate degree & 7 & $3.72 \%$ \\
\hline Master degree & 22 & $11.70 \%$ \\
\hline Bachelor Degree & 126 & $67.02 \%$ \\
\hline Diploma & 33 & $17.55 \%$ \\
\hline High school & 7 & $3.72 \%$ \\
\hline Intermediate School & 0 & $0.00 \%$ \\
\hline Primary School & 0 & $0.00 \%$ \\
\hline Not educated & 0 & $0.00 \%$ \\
\hline Answered question & 188 & $100 \%$ \\
\hline Skipped question & 0 & \\
\hline \multicolumn{3}{|l|}{ The current medications } \\
\hline Diabetic Medication & 26 & $13.83 \%$ \\
\hline Antihypertensive Medication & 28 & $14.89 \%$ \\
\hline Cardiac Medication & 7 & $3.72 \%$ \\
\hline Asthma Medication & 16 & $8.51 \%$ \\
\hline Derma Medication & 18 & $9.57 \%$ \\
\hline Anti-Rheumatic & 13 & $6.91 \%$ \\
\hline Do not take anything now & 125 & $66.49 \%$ \\
\hline Others & 27 & $14.36 \%$ \\
\hline Answered question & 188 & $100 \%$ \\
\hline Skipped question & 0 & \\
\hline \multicolumn{3}{|c|}{ Number of current medication taken } \\
\hline Nothing & 121 & $66.12 \%$ \\
\hline 1 & 29 & $15.85 \%$ \\
\hline 2 & 17 & $9.29 \%$ \\
\hline 3 & 7 & $3.83 \%$ \\
\hline 4 & 2 & $1.09 \%$ \\
\hline 5 & 2 & $1.09 \%$ \\
\hline 6 & 2 & $1.09 \%$ \\
\hline 7 & 3 & $1.64 \%$ \\
\hline 8 & 0 & $0.00 \%$ \\
\hline 9 & 0 & $0.00 \%$ \\
\hline 10 & 0 & $0.00 \%$ \\
\hline more than 10 & 0 & $0.00 \%$ \\
\hline Answered question & 183 & \\
\hline Skipped question & 5 & \\
\hline
\end{tabular}


Table 2: The healthcare provider's perception about medications.

\begin{tabular}{|c|c|c|c|c|c|c|c|c|c|}
\hline \multirow[t]{2}{*}{ No } & \multirow[t]{2}{*}{ Perceptions Inquiries } & $\begin{array}{l}\text { Response } \\
\text { Count }\end{array}$ & $\begin{array}{l}\text { Response } \\
\text { Percent }\end{array}$ & $\begin{array}{l}\text { Response } \\
\text { Count }\end{array}$ & $\begin{array}{l}\text { Response } \\
\text { Percent }\end{array}$ & $\begin{array}{l}\text { Response } \\
\text { Count }\end{array}$ & $\begin{array}{l}\text { Response } \\
\text { Percent }\end{array}$ & \multirow[t]{2}{*}{$\begin{array}{l}\text { answered } \\
\text { question }\end{array}$} & \multirow[t]{2}{*}{$\begin{array}{l}\text { skipped } \\
\text { question }\end{array}$} \\
\hline & & \multicolumn{2}{|l|}{ Always } & \multicolumn{2}{|l|}{ Sometimes } & \multicolumn{2}{|l|}{ Never } & & \\
\hline 1 & $\begin{array}{l}\text { Are you having difficulty reading the } \\
\text { name of your medicine }\end{array}$ & 10 & $5.43 \%$ & 69 & $37.50 \%$ & 105 & $57.07 \%$ & 184 & 4 \\
\hline \multirow[t]{2}{*}{2} & $\begin{array}{l}\text { Do you avoid going to the hospital } \\
\text { expected symptoms would subside? }\end{array}$ & 46 & $24.73 \%$ & 123 & $66.13 \%$ & 17 & $9.14 \%$ & 186 & 2 \\
\hline & & \multicolumn{2}{|l|}{ Yes } & \multicolumn{2}{|l|}{ No } & \multicolumn{2}{|l|}{ Others } & & \\
\hline 3 & $\begin{array}{l}\text { Can you read the expiration date } \\
\text { printed on the medication }\end{array}$ & 159 & $85.48 \%$ & 20 & $10.75 \%$ & 7 & $3.76 \%$ & 186 & 2 \\
\hline 4 & $\begin{array}{l}\text { Do you believe that the drug } \\
\text { information given by healthcare } \\
\text { professionals enough }\end{array}$ & 58 & $31.18 \%$ & 119 & $63.98 \%$ & 9 & $4.84 \%$ & 186 & 2 \\
\hline 5 & $\begin{array}{l}\text { Do you feel that your knowledge of } \\
\text { prescribed medications for you is } \\
\text { good enough? }\end{array}$ & 110 & $59.14 \%$ & 68 & $36.56 \%$ & 8 & $4.30 \%$ & 186 & 2 \\
\hline 6 & $\begin{array}{l}\text { Have you ever tacked a drug you do } \\
\text { not have any prior information about }\end{array}$ & 60 & $32.26 \%$ & 122 & $65.59 \%$ & 4 & $2.15 \%$ & 186 & 2 \\
\hline 7 & $\begin{array}{l}\text { Is it possible to describe another } \\
\text { drug to a person suffering from the } \\
\text { same illness? }\end{array}$ & 85 & $45.70 \%$ & 97 & $52.15 \%$ & 4 & $2.15 \%$ & 186 & 2 \\
\hline \multirow[t]{2}{*}{8} & $\begin{array}{l}\text { Is it possible to use a drug without a } \\
\text { prescription? }\end{array}$ & 130 & $70.27 \%$ & 51 & $27.57 \%$ & 4 & $2.16 \%$ & 185 & 3 \\
\hline & & \multicolumn{2}{|c|}{ Take the entire Course } & \multicolumn{2}{|c|}{$\begin{array}{l}\text { Stop the medications } \\
\text { when you feel better }\end{array}$} & \multicolumn{2}{|l|}{ Others } & & \\
\hline 9 & $\begin{array}{l}\text { Do you take the entire Course or you } \\
\text { just stop the medication when you } \\
\text { feel better }\end{array}$ & 116 & $63.04 \%$ & 65 & $35.33 \%$ & 3 & $1.63 \%$ & 184 & 4 \\
\hline
\end{tabular}

perception towards medications. Several essential medications courses delivered to the physicians, pharmacists and nurses in the past years. Another service provided to all healthcare professionals to correct the attitudes and perception of medications was the network of drug information centers services. They are receiving inquiries calls from them over $24 / 7$ from all healthcare professionals. ${ }^{[16]}$ The investigator wishes to explore the perception of healthcare professionals toward medications. The finding showed that not one third of them had difficulty in reading drug name and only a few had problems with an expiry date of the medication, maybe because of different specialty or not familiar with drug manufacturers process. The finding showed that is healthcare professionals one-third of them usage medications without prior information and two third of them prescribed the medications with same conditions. These findings are unexpected because they should know the medications before usage. However, it is expected to prescribe the medications or use the medications without prescription especially with over the counter medications. One-third of healthcare professionals noncompliance with their medications and that is not expected sure had good medications knowledge. It may be they are buzzy to take the medication regularly and on time. Two third of healthcare providers through drug information given to healthcare professionals is not adequate and be third of them does not have sufficiently of drug information knowledge. That is related to a week healthcare education from the pharmacy or the pharmaceutical services do contain drug information services at the organization. Also, the pharmacology education at healthcare professional's school is not adequate for them. Also, the inadequate knowledge of medication mostly attributed to the lack of communication from the medical practitioners due to the high patient load. The pharmacists in the pharmacy would help improve patients' knowledge of medication use. However, sometimes the lack of drugs in the hospital forces patients to go out of the hospital with half-filled prescriptions or no drugs This poses a question on whether healthcare is equitable from the standpoint of proper information about medication. ${ }^{[2]}$ The Healthcare professional knowledge about prescribed medication is an essential factor in determining their compliance a patient and outcome of a disease. ${ }^{[3]}$ The results show that healthcare practitioners are not fully aware of drugs prescriptions and need to know more and learn about prescriptions and give them great importance because the attitude toward medication In Saudi Arabia Plays an important role and counseling sessions were able to produce statistically significant results. ${ }^{[17]}$ Most of the results could not compare with other studies because it seems that this the first study which discussed the healthcare perception of medications with particular information.

\section{CONCLUSION}

In a resource-poor setting with Limited Proficiency, lower level of education and misperception of illness severity maybe resulted in reduced knowledge on prescribed medications. Furthermore, the being educated by a healthcare professional significantly improved knowledge. To better educate clinicians and pharmacists about medications, some professionals Should be resourced. These resources include information specific to classes of medications and medication types that have high specific potential, as well as suggestions on how to assess function and Counsel Participant's information and knowledge of Medication's Perception.

\section{ACKNOWLEDGEMENT}

None

\section{CONFLICT OF INTEREST}

None 


\section{ABBREVIATIONS}

KSA: Kingdom of Saudi Arabia; MOH: Ministry of Health; CBAHI: Saudi Center for Accreditation of Healthcare Institutions.

\section{REFERENCES}

1. Briggs AL, Jackson TR, Bruce S, Shapiro NL. The development and performance validation of a tool to assess patient anticoagulation knowledge\{star, open\}. Res Soc Adm Pharm. 2005;1(1):40-59.

2. Ssemaluulu R, Adome R. Patients ' knowledge of medication use as an equity issue in health care : Do health workers pay attention to this?. 2006. Available from: http://www.equinetafrica.org/sites/default/files/uploads/documents/ CBP3EHSadome.pdf

3. Franks TJ, Burton DL, Simpson MD. Patient medication knowledge and adherence to asthma pharmacotherapy: a pilot study in rural Australia. Ther Clin Risk Manag. 2005;1(1):33-8.

4. Ghimirey A, Sapkota B, Shrestha S, Basnet N, Shankar PR, Sapkota S. Evaluation of pharmacist counseling in improving knowledge, attitude and practice in chronic kidney disease patients. SAGE Open Med. 2013;1:205031211351611.

5. Mendelson D, Ramchand R, Abramson R, Tumlinson A. Prescription drugs in nursing homes: managing costs and quality in a complex environment. NHPF Issue Br Natl Heal Policy Forum Georg Washington Univ. 2002;(784):118.

6. Salhia HO, Ali A, Rezk NL, El Metwally A. Perception and attitude of physicians toward local generic medicines in Saudi Arabia: A questionnaire-based study. Saudi Pharm J. 2015;23(4):397-404.

7. Al-Mohamadi A, Badr A, Mahfouz LB, Samargandi D, Al Ahdal A. Dispensing medications without prescription at Saudi community pharmacy: Extent and perception. Saudi Pharm J. 2013;21(1):13-8.

8. Krishnan V, Thirunavukkarasu J. Assessment of knowledge of self-blood glucose monitoring and extent of self-titration of Anti-Diabetic drugs among diabetes mellitus Patients - A cross-sectional, community-based study. J Clin Diagnostic Res. 2016;10(3): FC09-FC11.

9. Alkatheri AM, Bustami R, Albekairy AM, Almodaimegh H, Alghamdi S, Alharbi S, et al. Pharmacy educators' knowledge of medication safety and their perception toward its integration into the doctor of pharmacy curriculum in Saudi Arabia. Am J Pharm Educ. 2017;81(2).

10. Lindsay BR, Olufade T, Bauer J, Babrowicz J, Hahn R. Patient-reported barriers to osteoporosis therapy. Arch Osteoporos. 2016;11(1):3-10.

11. Medication Management (MM). In: National Hospital Standards. $2^{\text {nd }}$ Editio. Saudi Central Board for Accreditation of Healthcare Institutions.; 2015;194-211. Available from: http://www.cbahi.gov.sa

12. Comprehensive Accreditation Manuals. Joint Commission Resources. Available from: http://www.jcrinc.com/store/publications/manuals/

13. Acheivements 2013. $1^{\text {st }}$ Ed. Ministry of Health, Saudi Arabia. 2011;132-135. Available from: http://sgsminsk.by/_/media/Global/Documents/Technical Documents/Technical Datasheets/SGS-PCA-SA-Datasheet SFDA-A4-EN11-V2.pdf

14. Alomi YA, Alghamdi SJ, Alattyh RA. Strategic Plan of General Administration of Pharmaceutical Care at Ministry of Health in Saudi Arabia 2012-2022. J Pharm Pharm Sci. 2015;1(3):1-8.

15. Alomi YA. National Medication Safety Program at Ministry of Health in Saudi Arabia. J Pharmacovigi. 2015;3(5):1-2.

16. Alomi YA, Mudaiheem H A. National Drug Information Center Services through Ministry of Health Hotline Calling Center (937) in Saudi Arabia. Adv Pharmacoepidemiol Drug Saf. 2016;5(1)

17. Alshammari TM. Patient's medicinal knowledge in Saudi Arabia: Are we doing well?. Saudi Pharm J. 2016;24(5):560-2. 